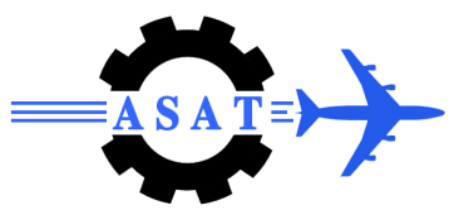

\title{
A Real Options Approach to Implement Supply Chain Flexibility under Outsourcing Conditions
}

\author{
A.M. Osman ${ }^{*}$, Nahed Sobhy ${ }^{\dagger}$, Ahmed Mahmoud ${ }^{\star}$, Mohamed Awad ${ }^{\star}$
}

\begin{abstract}
Supply chain flexibility has long been recognized as an important strategic and operational characteristic of manufacturing systems and organizations. In general, supply chain flexibility allows firms to compete more effectively in a world of short product life cycles, rapid product development, and substantial demand and/or price uncertainty. Outsourcing option is one of the most important strategic decisions which can improve organization's supply chain flexibility.

A real options approach is a tool, which can estimate the value of flexibility and is used to determine the optimum strategy to manage this flexibility. The main objective of this paper is to develop a simulation model to evaluate the option value of outsourcing and examine its effect on supply chain flexibility using real options approach. The proposed model demonstrates the application of real options approach to value outsourcing option in order to enhance the organization's supply chain flexibility through four variables: price, quality, delivery, and switching ability. Several examples through different scenarios are presented, carried out and simulated using Monte Carlo simulation. The proposed approach gives decision makers a way to choose the appropriate outsourcing strategy based on an integrated view of market dynamics.
\end{abstract}

Keywords: Simulation - Monte Carlo simulation - Supply chain flexibility - Outsourcing Option - Real options approach.

\section{Introduction}

Nowadays, many companies are facing uncertain environment, short product life cycles, frequent and unpredictable changes in demand, and global logistics issues. This has led companies to put more pressure on their ability to change or react to environmental uncertainty with little penalty in their performance. In other words, companies have become more aware of the need of flexibility.

Supply Chain Flexibility allows firms to compete more effectively in an environment of uncertainty. As Supply Chain flexibility is commonly associated with the ability to change or react, several frameworks are proposed in which supply chain flexibility is analyzed in four dimensions: supply (outsourcing), manufacturing, distribution, and product development, [1].

\footnotetext{
M.Sc. Student, Faculty of Engineering, Ain Shams University, Egypt; Engineer, Al Khorayef Petroleum, Egypt; E-mail: a_m_osman@hotmail.com.

$\dagger$ Prof., Design and Production Engineering Department, Faculty of Engineering, Ain Shams University, Egypt.

Assistant Prof., Design and Production Engineering Department, Faculty of Engineering, Ain Shams University, Egypt.
} 
Outsourcing is the transfer of responsibility for a business function from an employee group to a non-employee group, [2]. Outsourcing is increasingly viewed as a way to reduce the focus on a non-value added activities by using a specialized service provider for those functions; it allows companies to focus on their core competence.

One may consider flexibility as arising from the formal decision problem in which the choices among future options are affected. Flexibility is the measure of potential and will be relevant only to the future. It cannot be measured with unlike attributes, such as throughput, cost, or quality, which can be quantitatively measured in the present. As a result, flexibility can only be estimated and evaluated not measured; even so, it is important to evaluate it carefully, and to ensure that estimates are reasonable, [3].

Decision analysis and real option approach are used to evaluate flexibility, because option creates flexibility. Real Option Analysis is a way to apply option techniques to engineering and business projects. Specifically, it provides a way of valuing flexibility. It also provides a new way of thinking about flexibility in general, [4].

The term real option was premised on the Nobel Prize winning Options Pricing Theory developed by Fischer Black and Myron Scholes for the valuation of market tradable assets, , [5]. Real options provide managers with flexibility by allowing them to take an action only if it will be beneficial. If not, they simply choose not to exercise the option and in this way can limit their losses.

In the present paper, a simulation model to evaluate the option value of outsourcing is built and the actual effect of outsourcing on supply chain flexibility through imperial data is simulated. The effectiveness of the outsourcing option on supply chain flexibility is concluded, and the best model to enhance the organization's supply chain flexibility through the four variables considered (price, quality, delivery, and switching) ability is reached.

\section{Proposed Model}

In this section, the proposed model for outsourcing will be discussed. This model is based on Aktan's model which provided a framework for the model of product outsourcing, [8].

Aktan developed a general framework for evaluating the total cost reduction from outsourcing $\mathrm{R}_{\mathrm{r}}(\mathrm{t})$ from a global network of suppliers when the purchasing firm faces uncertain exchange rates, [8].

The present paper develops Aktan's model to four variables model to assess the option value of outsourcing, taking into consideration the price, the quality, the delivery, and the switching ability.

For any item that is a part of a final product, the total cost reduction from outsourcing has the following input parameters considered during the time interval beginning at time t:

- Unit production cost of the item $\mathrm{P}_{1}(\mathrm{t})$.

- Unit outsourcing price of the item $\mathrm{P}_{2}(\mathrm{t})$.

- Unit delivery cost of the outsourced item $\mathrm{P}_{3}(\mathrm{t})$.

- Demand D

- No of defects / No. Of total parts Q ratio.

- No of defects items return $Q_{\text {returns. }}$ 
- Actual delivery time $\mathrm{D}_{\mathrm{a}}(\mathrm{t})$.

- Expected delivery time $\mathrm{D}_{\mathrm{e}}(\mathrm{t})$.

- Penalty cost per unit time $D_{P}$.

- Fees to be under call F.

- Termination penalty TP.

The manufacturer can change the decision about outsourcing at each time interval (in our case each interval will be one year). The proposed model for outsourcing is presented in Figure 1, where the supplier can be involved in the production cycle depending on the value of the outsourcing option.

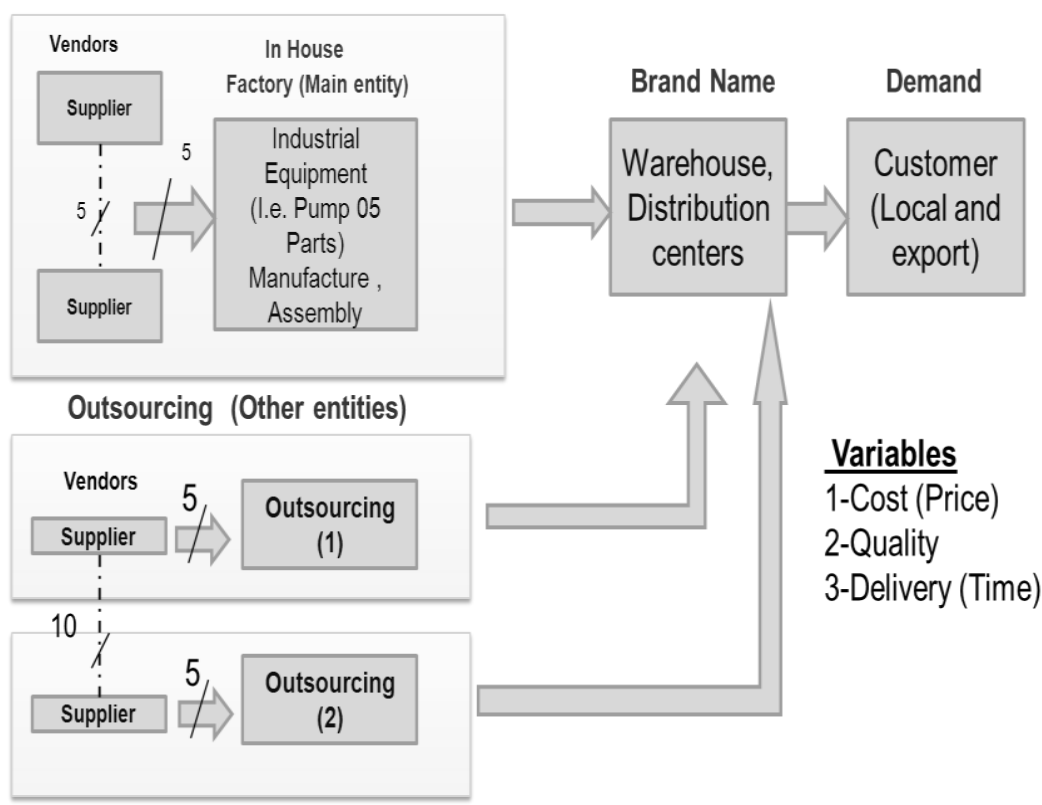

Fig. 1 Proposed model for outsourcing

Total cost reduction from outsourcing $\mathrm{R}_{\mathrm{r}}(\mathrm{t})$ during the time interval that begins at time $t$ is calculated from equation (1).

$$
R_{r}(t)=\left[P_{1}(t) \times D\right]-R_{t}(t)
$$

where $\mathrm{P}_{1}(\mathrm{t})$ is the unit production cost, and $\mathrm{D}$ is the demand, $\mathrm{R}_{\mathrm{t}}(\mathrm{t})$ is the total expected cost of outsourcing,

The total expected cost of outsourcing $R_{t}(t)$ is calculated from equation (2) during the time interval beginning at a time $t$ where $R_{1}(t)$ is the price cost, $R_{2}(t)$ is the quality cost, $R_{3}(t)$ is the delivery cost, and $S_{\mathrm{w}}$ is the switching cost.

$$
R_{t}(t)=\left[R_{1}(t)+R_{2}(t)+R_{3}(t)+S_{w}\right]
$$

The price cost $R_{1}(t)$ calculated from equation (3) by adding a unit outsourcing cost $P_{2}(t)$ to a unit delivery cost of the outsourced item $\mathrm{P}_{3}(\mathrm{t})$, and multiplying them by demand $\mathrm{D}$.

$$
\mathrm{R}_{1}(\mathrm{t})=\left[\mathrm{P}_{2}(\mathrm{t})+\mathrm{P}_{3}(\mathrm{t})\right] \times \mathrm{D}
$$


The unit outsourcing cost $\mathbf{P}_{\mathbf{2}}(\mathbf{t})$ calculated from equation (4) by multiplying unit production $\operatorname{cost} \mathbf{P}_{\mathbf{1}}(\mathbf{t})$ by supplier price ratio.

$$
\mathrm{P}_{2}(\mathrm{t})=\mathrm{P}_{1}(\mathrm{t}) \times \text { Supplier Price ratio }
$$

The unit production cost $\mathbf{P}_{\mathbf{1}}(\mathbf{t})$ calculated from equation (5)

$$
\mathrm{P}_{1}(\mathrm{t})=(\text { Item Weight } \times \text { Material Cost })+\text { Machining Cost }
$$

The quality cost $\mathbf{R}_{\mathbf{2}}$ (t) calculated from equation (6) by adding ( No of defects / No. of total parts) $\mathbf{Q}$ ratio to No of defects items return $\mathbf{Q}$ returns, and multiplying them by a unit outsourcing $\operatorname{cost} \mathbf{P}_{\mathbf{2}}(\mathbf{t})$.

$$
\mathbf{R}_{\mathbf{2}}(\mathbf{t})=\left[\mathbf{Q}_{\text {ratio }}+\mathbf{Q}_{\text {returns }}\right] \times \mathbf{P}_{\mathbf{2}}(\mathbf{t})
$$

The delivery cost $\mathbf{R}_{\mathbf{3}}$ (t) calculated from equation (7) by subtract actual delivery time $\mathrm{Da}(\mathrm{t})$ from expected delivery time $\mathrm{De}(\mathrm{t})$, and multiplying them by penalty cost per unit time $\mathrm{D}_{\mathrm{P}}$.

$$
R_{3}(t)=\left|\left[D_{e}(t)-D_{a}(t)\right] \times D_{P}\right|
$$

The switching ability cost $S_{\mathrm{w}}$ calculated from equation (8) by adding fees to be under call $\mathbf{F}$ to termination penalty $\mathbf{T}_{\mathbf{P}}$.

$$
S_{w}=T_{P}+F
$$

Fees to be under call $\mathbf{F}$ can be calculated by multiplying $R_{1}(t)$ by supplier penalty factor, and termination penalty $\mathbf{T}_{\mathbf{P}}$ can be calculated by multiplying $\mathrm{R}_{1}(\mathrm{t})$ by supplier fees factor.

Figure 2 shows the relationship between the variables, and their effect on outsourcing decisions.

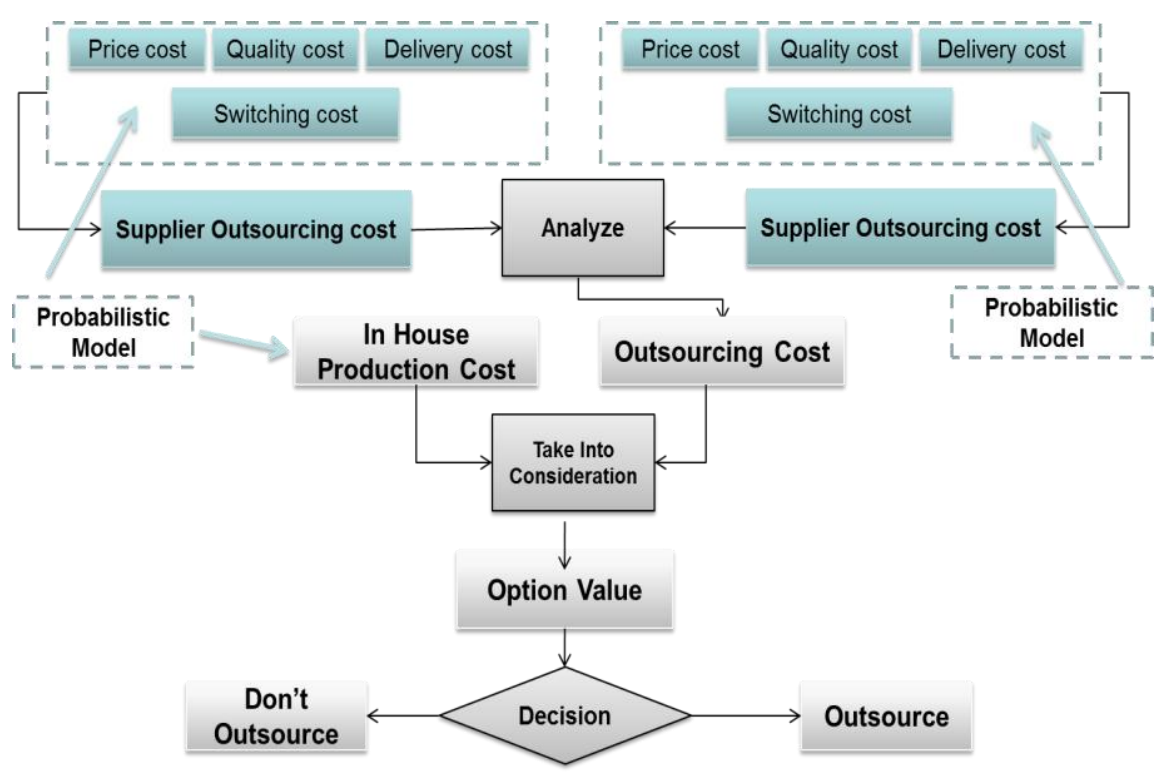

Fig. 2 Relationship between the Variables, and their Effect on Outsourcing Decisions 
If the outsourcing cost of the item is higher than the production cost, then the manager has two options, producing in-house or outsource to meet certain specifications. Each option has a confidence level which reflects involving the uncertainty factor in the proposed model.

Figure 3 shows possible options available through three paths. The first path presents in-house production. The second path presents outsourcing decision with a certain supplier, and the third path presents outsourcing with an alternative supplier. Depending on option value, decision will be made to go with any of these paths.

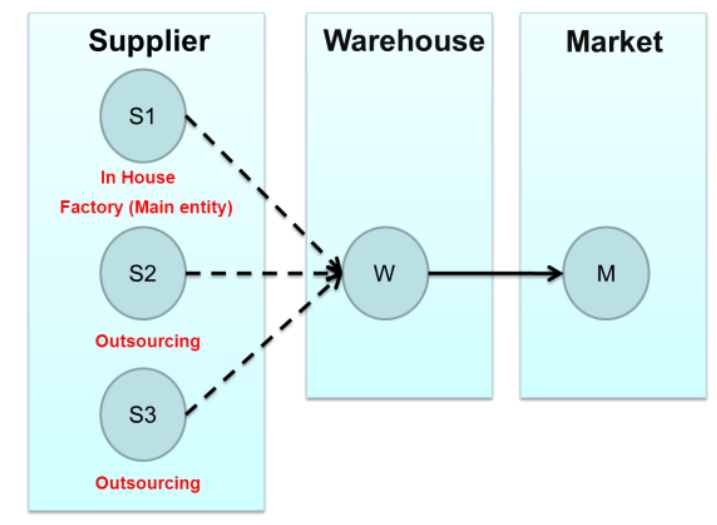

Fig. 3 Possible Options Available

\section{Theoretical Background}

To value the model, Monte Carlo simulation will be applied. Simulation models may be used to give numerous possible paths of evolution for state variables from the present to the final date in the option, [7]. In the commonly used Monte Carlo simulation method, the optimal strategy on each path is determined as following:

$$
\mathrm{dS}=\mu \mathrm{Sdt}+\sigma \mathrm{Sdz}
$$

where $\mathrm{z}$ is a Wiener process, $\mu$ is the expected rates $(\mu=\mathrm{r}$ ), and $\sigma$ is the volatility (deviation). To simulate the path followed by $\mathrm{S}$, the life of the variable is divided into $\mathrm{n}$ short intervals of length $\Delta \mathrm{t}$ as shown in equation (10):

$$
\mathrm{S}(\mathrm{t}+\Delta \mathrm{t})-\mathrm{S}(\mathrm{t})=\mu \mathrm{S}(\mathrm{t}) \Delta \mathrm{t}+\sigma \mathrm{S}(\mathrm{t}) \varepsilon \sqrt{ } \Delta \mathrm{t}
$$

where $\mathrm{S}(\mathrm{t})$ denotes the value of $\mathrm{S}$ at time $\mathrm{t}$, and $\varepsilon$ is a random sample from a normal distribution with a mean zero and unit standard deviation. This enables the value of $\mathrm{S}$ at time $\Delta t$ to be calculated from the initial value of $\mathrm{S}$, the value at time $\Delta \mathrm{t}$ is calculated from the value at time $\Delta \mathrm{t}$, and so on. One simulation trial involves constructing a complete path for $\mathrm{S}$ using $\mathrm{n}$ random samples from a normal distribution, [7].

From Ito’s lemma, [7].

$$
d \ln S=\left(\hat{\mu}-\frac{\sigma^{2}}{2}\right) d t+\sigma d z
$$




$$
\ln S(t+\delta t)-\ln S(t)=\left(\hat{\mu}-\frac{\sigma^{-}}{2}\right) \delta t+\sigma \epsilon \sqrt{\delta t}
$$

Or equivalently

$$
S(t+\delta t)=S(t) \exp \left[\left(\hat{\mu}-\frac{\sigma^{2}}{2}\right) \delta t+\sigma \epsilon \sqrt{\delta t}\right]
$$

This equation is used to construct a path for $\mathrm{S}$ in a similar way to Equation (12). Whereas Equation (12) is true only in the limit as $\Delta t$ tends to zero. Equation (13) is exactly true for all $\Delta \mathrm{t},[7]$.

In the present model, Equation (11) is used to generate values for uncertainty variables for each $t$. The average of $F(t)=\max \left\{0, R_{r}\right\}$ values are then calculated.

\section{Case Study}

In this section, liquid Ring Vacuum Pump will be discussed as a case study. A simulation case will be explained. Finally, analysis and interpretation of simulation results will be highlighted.

Figure 4 shows an isometric drawing of liquid ring Vacuum Pump assembly, [9]. This assembly considers only casting parts, as the purchased parts are standard parts (I.e. nuts, bolts, washers, etc....), and can be purchased from any supplier with standard prices.

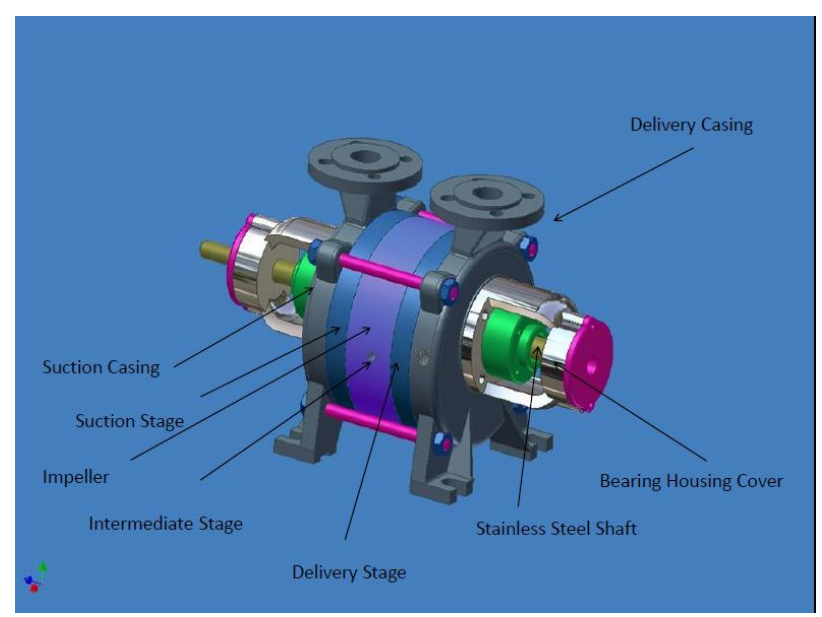

Fig. 4 Pump Assembly Isometric Drawing

This case study is done from practical experience with cooperating with a pump leading company in Egyptian market. All values and assumptions used in this paper are concluded from practical experience and according to the pump company records.

In the proposed model, supplier inputs considered as managerial inputs which can guide the evaluation of each option. Table 1 shows supplier inputs / managerial inputs and their extreme limits according to practice and Egyptian law. 
Table 1 Supplier Inputs / Managerial Inputs and Their Extreme Limits

\begin{tabular}{l||l|l}
\hline \hline & \multicolumn{1}{|c}{$\begin{array}{c}\text { Supplier Inputs / Managerial } \\
\text { Inputs }\end{array}$} & \multicolumn{1}{c}{ Extreme Limit } \\
\hline Price Cost & Supplier Price Cost & $\begin{array}{l}75 \% \text { to } 85 \% \text { from the production } \\
\text { cost according to practice }\end{array}$ \\
\hline Quality Cost & $\begin{array}{l}\text { No of defect / No of Total Parts } \\
\text { Q ratio }\end{array}$ & $1 \%: 10 \%$ according to practice \\
\hline $\begin{array}{l}\text { Delivery } \\
\text { (Time) Cost }\end{array}$ & Supplier Delivery Delay & $\begin{array}{l}0 \text { Week : 3 Weeks according to } \\
\text { Practice }\end{array}$ \\
\hline $\begin{array}{l}\text { Switching } \\
\text { Cost }\end{array}$ & $\begin{array}{l}\text { Supplier's Penalty Factor } \\
\text { Supplier's fees Factor }\end{array}$ & $\begin{array}{l}0 \%: 5 \% \text { according to Egyptian law } \\
0 \%: 7 \% \text { according to Egyptian law }\end{array}$ \\
\hline
\end{tabular}

From supplier parameters' upper and lower limits, we can create difference combinations and scenarios to evaluate the option.

Table 2 presents the scenario table / Parameters Range, which describes example scenarios that can be applied on the model: lowest price, best quality, shortest delivery, and switching ability. Each scenario represented by certain factors concluded from lower and upper limits of the parameters.

Table 2. Scenario Table / Parameters Range

\begin{tabular}{l|c|c|c|c|c}
\hline Scenario Table / Parameters Range & Price & Quality & Delivery & \multicolumn{2}{|c}{ Switching } \\
\hline Lowest Price Scenario & 0.75 & 0.1 & 3 & 0.05 & 0.07 \\
\hline Best Quality Scenario. & 0.85 & 0.01 & 3 & 0.05 & 0.07 \\
\hline Shortest Delivery Scenario. & 0.85 & 0.1 & 0 & 0.05 & 0.07 \\
\hline Switching Ability Scenario & 0.85 & 0.1 & 3 & 0 & 0 \\
\hline
\end{tabular}

Note: all values are percentages from the production costs, except the delivery is calculated as no. of weeks.

In the left side, example scenarios are defined, and in the left box, four factors are defined (Supplier price cost, supplier quality ratio, and supplier delivery delay and supplier termination penalty), for each scenario.

This table can be considered as a managerial table, which can show quick model information. By varying these factors infinite number of alternatives can be created, which reflects the supply chain flexibility and enables managers to choose between different options.

In this section, the lowest price scenario will be discussed. Table 3 shows the calculations after entering the lowest price scenario inputs.

The basic process for using Oracle Crystal Ball Package is to

1. Build a spreadsheet model that describes an uncertain situation.

2. Run a simulation on it.

3. Analyze the results 
The simulation process steps are described in Figure 5

Table 3 Calculation Table

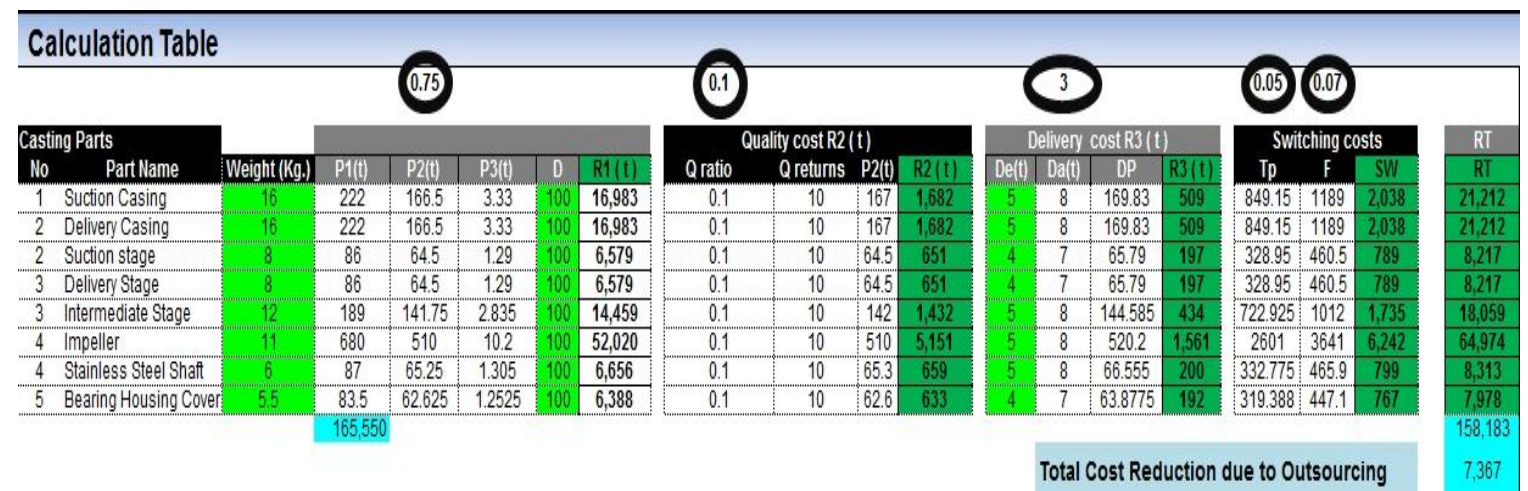

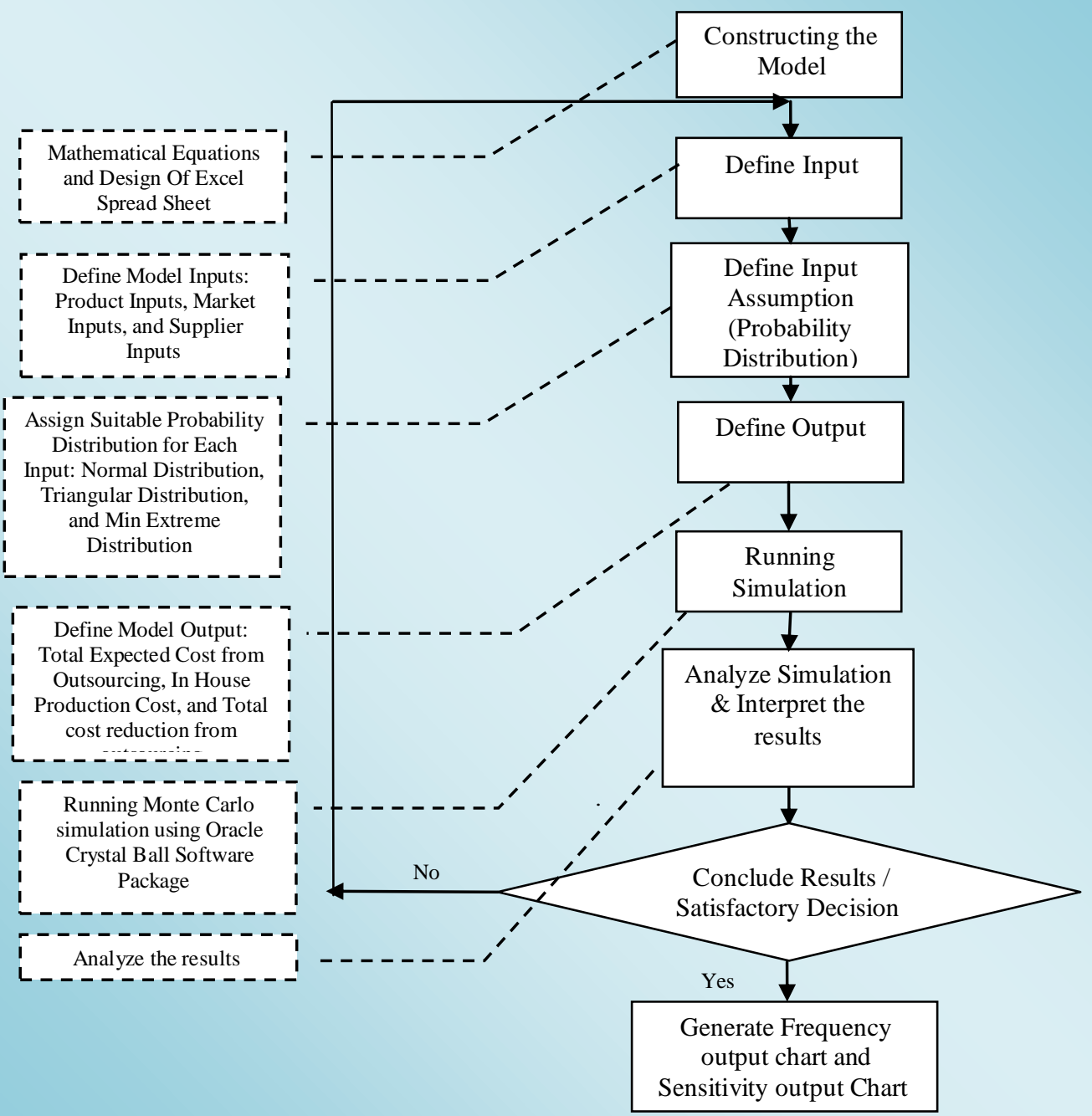

Fig. 5 Simulation Process Steps 


\section{Simulation and Results}

Total cost reduction from outsourcing $\mathrm{R}_{\mathrm{r}}(\mathrm{t})$ during the time interval that begins at time $t$ for lowest price scenario at deterministic calculation can be calculated as following:

$\checkmark$ From equation (1) and Table 3: $\mathbf{R}_{\mathbf{r}}(\mathbf{t})=\left[\mathbf{P}_{\mathbf{1}}(\mathbf{t}) \times \mathbf{D}\right]-\mathbf{R}_{\mathbf{t}}(\mathbf{t})=7,367$ EGP

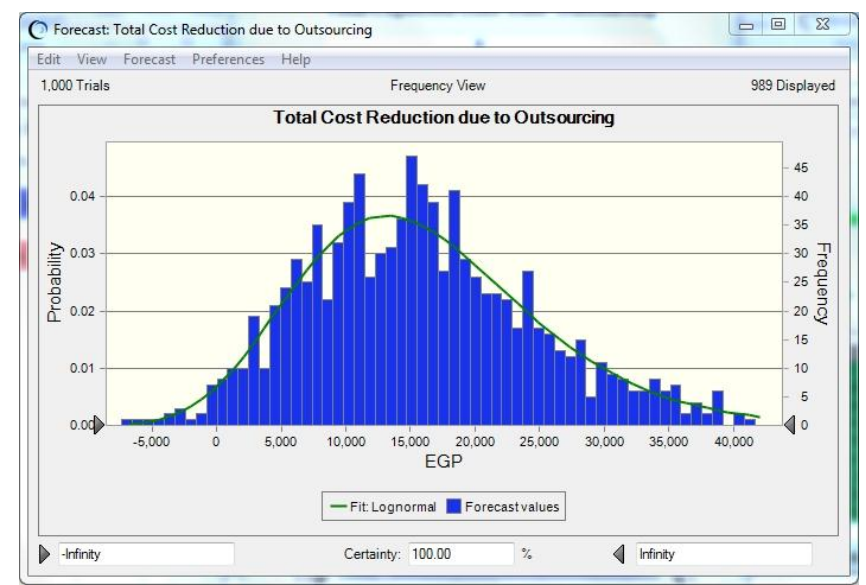

Fig. 6 Output Frequency Charts of Total Cost Reduction From Outsourcing $R_{r}(t)$ In Lowest Price Scenario.

After running the Oracle Crystal Ball Package Software, output frequency distribution is generated. Figure 6 shows the output frequency charts of total cost reduction from outsourcing $\mathrm{R}_{\mathrm{r}}(\mathrm{t})$ in lowest price scenario.

Tables 4 shows output data conducted from the frequency chart of total cost reduction from outsourcing $\mathrm{R}_{\mathrm{r}}(\mathrm{t})$ in Lowest Price Scenario.

Table 4 Data Conducted From The Frequency Chart of Total Cost Reduction From Outsourcing $R_{r}(t)$ in Lowest Price Scenario.

\begin{tabular}{l|l}
\hline \multicolumn{1}{c|}{ Case Name } & \multicolumn{1}{c}{ Lowest Price Scenario } \\
\hline No. of Probabilistic Variables Tested & 4 \\
\hline Frequency Chart Name & Total Cost Reduction From Outsourcing Rr (t) \\
\hline No Of Trials Done & 1000 \\
\hline Confidence level & $100 \%$ \\
\hline Nearest Distribution To Be Fit & Lognormal \\
\hline Total Cost Reduction From Outsourcing Rr $(\mathrm{t})$ & 7,367 EGP \\
\hline Mean Value & 16,532 EGP \\
\hline
\end{tabular}

$\checkmark$ Applying Real Option Approach : F (t) $=\max \{0,16,532\}=16,532$ EGP

$\checkmark$ Using Microsoft Excel NPV for the option value assuming that the rate will be $10 \%$ : NPV $(10 \%, 16,532)=15,029$ EGP 
In the lowest price scenario, total cost reduction from outsourcing $R_{r}(t)=15,029$ EGP for $100 \%$ certainty.

In $100 \%$ confidence level, manager will have the flexibility to exercise the outsourcing option for 1 year time interval against option price equal 15, 029 EGP

Nearest standard distribution is lognormal for total cost reduction from outsourcing $R_{r}(t)$ in lowest price scenario.

The Frequency distribution chart also shows the certainty range for the output. A confidence level here is $100 \%$ since the initial certainty range includes all possible ranges. By moving the grabber or modify the confidence level, wide range of confidence levels can be obtained.

By varying the confidence level to $75 \%$ different values will be generated which can affect the manger decision by including uncertainty factors in the decision.

\section{Summery and Conclusion}

Supply Chain Flexibility affects as an important strategic and operational characteristic on any organization. It has the ability to change or react to environmental uncertainty with little penalty in time, effort, cost or performance. Supply Chain Flexibility allows firms to compete more effectively in an environment of uncertainty. A real options approach estimates the value of flexibility and is used to determine the optimum strategy to manage the flexibility.

In this paper, an outsourcing model has been developed and simulated to evaluate the option value of outsourcing and examine its effect on supply chain flexibility using real options approach.

The proposed model demonstrates the application of real options approach to value outsourcing option in order to enhance the organization's supply chain flexibility through four variables: price, quality, delivery, and switching ability. Case study is presented, carried out and simulated using Monte Carlo simulation.

The model considers four managerial variables obtained from supplier status, which can guide the model to evaluate the option value. Simulation is run by the generation of random number depending on probability distribution assigned to each input, and then goes through model equations until finding the option value. Confidence level can be changed to help the manager to evaluate the contracting option considering uncertain environment. Managers can decide if they can outsource or not depending on in house production value and outsourcing option value.

Confidence level can be considered as managerial tool to make a decision. Manager can change the confidence level to know his limits or move the grabber to his limits to conclude the confidence level.

The proposed approach gives decision makers a way to choose the appropriate outsourcing strategy based on an integrated view of market dynamics.

\section{Acknowledgment}

The authors would like to express their deepest gratitude to Dr. Khaldon Taha Meselhy, MTC, for his helpful remarks. 


\section{References}

[1] Tachizawa1T, (2005), "Drivers and Sources of Supply Flexibility: An Exploratory Study" ESADE Business School - Universidad Ramon Llull.

[2] Bindiya Vakil. (2002), "Design Outsourcing in the High-Tech Industry and its Impact on Supply Chain Strategies", Master of Engineering in Logistics, Sardar Patel University.

[3] Upton, D.M. (1994),"The Management of Manufacturing Flexibility", California Management Review, Vol 36 No 2, PP. 72-89.

[4] Prasad Kodukula. (2006), "Project Valuation Using Real Options a Practitioner's Guide", J. Ross Publishing, Inc.

[5] Black, F. and Scholes, M. (1973), " The Pricing of Options and Corporate Liabilities". Journal of Political Economy 81:637-659.

[6] Carlos Trejo. (2002), "Real Options: Understanding the Basic Concepts", Assistantship project for MABM degree.

[7] Hull, J. (1997),"Options, Futures, and other Derivatives Securities", Third Edition, Prentice Hall Englewood Cliffs, N.J.

[8] Mehmet Aktan. (2001), "A Real Options Design for Product Outsourcing" Proceedings of the 2001 Winter Simulation Conference.

[9] Helmut Bannwarth. (2005), "Liquid Ring Vacuum Pumps, Compressors and Systems"WILEY-VCH Verlag GmbH \& Co. KGaA, Weinheim.

[10] Oracle (2009), Oracle Crystal Ball user manual, Oracle. 